\title{
Enhanced Biotransformation of Triclocarban by Ochrobactrum sp. TCC-1 Under Anoxic Nitrate Respiration Conditions
}

\author{
Hui Yun ${ }^{1,2} \cdot$ Bin Liang ${ }^{1}$ Deyong Kong ${ }^{3}$ Zhiling $\mathrm{Li}^{4} \cdot$ Guoshu Qi ${ }^{3}$ Aijie Wang ${ }^{1,2,4}$
}

Received: 4 January 2017 / Accepted: 10 February 2017 / Published online: 22 February 2017

(C) Springer Science+Business Media New York 2017

\begin{abstract}
Antimicrobial triclocarban (3,4,4'-trichlorocarbanilide, TCC) is frequently detected in soils and sediments for the widely reclaim of sewage sludge or biosolid in recent decades. This resulted from a weak removal of TCC during wastewater treatment, and most of it adsorbed onto sewage sludge. As the toxicity and persistence of TCC in the environment, the elimination of TCC from the source of output is of great importance, particularly in anoxic process. In this study, the biotransformation of TCC by a newly isolated TCC-degrading strain Ochrobactrum sp. TCC-1 under anoxic conditions was investigated. By testing different carbon nitrogen ratios $(\mathrm{C} / \mathrm{N})$, it showed that nitrate could support the growth of strain TCC- 1 and enhance the hydrolysis of TCC to more biodegradable chloroanilines, especially with a higher $\mathrm{C} / \mathrm{N}$ of 10 and under anaerobic conditions. In wastewater sewage sludge, strain TCC-1 colonized and maintained the TCC-hydrolyzing activity
\end{abstract}

Electronic supplementary material The online version of this article (doi:10.1007/s00284-017-1214-1) contains supplementary material, which is available to authorized users.

Bin Liang

binliang@rcees.ac.cn

Aijie Wang

ajwang@rcees.ac.cn

1 Key Laboratory of Environmental Biotechnology, Research Center for Eco-Environmental Sciences, Chinese Academy of Sciences, Beijing 100085, China

2 University of Chinese Academy of Sciences, Beijing, China

3 Shenyang Academy of Environmental Sciences, Shenyang 110167, China

4 State Key Laboratory of Urban Water Resource and Environment, Harbin Institute of Technology, Harbin 150090, China under the nitrate respiration mode. These results would lay a basic foundation for the potential bioremediation of TCCcontaminated anoxic sites with TCC-degrading strain.

\section{Introduction}

Wastewater and biosolid from municipal wastewater treatment plants (WWTPs) have been encouraged to reclaim and reuse in a growing trend around the world [1]. This would be beneficial to the water shortage and reduction discharge of biosolid. In many countries, biosolid also has been used for landfilling and land application. It is estimated that around 7 million tons and 6.25 million tons of sewage sludge in the form of biosolid were released into environments every year in the USA and China, respectively [2,3]. Although through aerobic and/or anaerobic treatment, various insufficiently treated pharmaceuticals and personal care products (PPCPs) were still contained in municipal biosolid. One of these compounds, haloaromatic antimicrobial agent triclocarban (3,4,4'-trichlorocarbanilide, TCC), is typically difficult to be degraded in WWTPs and more than $70 \%$ is carried by biosolid at concentration of $\mathrm{mg}$ per $\mathrm{kg}[4,5]$. Its recalcitrance determines the persistence and high frequent detection of it in many natural aquatic environments and sediments [6,7]. Many investigations had reported the toxicity of TCC on aquatic organisms [8], and it also could be bioaccumulated in mammals to disturb the endocrine system and to cause the blood disorder and methemoglobinemia for humans [9]. More important, because of its germicidal properties, increased antibiotic-resistant microbes and genes could be induced $[10,11]$. Thus, TCC has been regarded as contaminants of emerging concern and much attention has been focused on the fate of the biosolid derived TCC. To decrease the input 
of TCC from biosolid or sewage sludge into environments, the removal of TCC during wastewater treatment played an important role, which may be realized by combining bioaugmentation on the basis of traditional methods. So far, TCC has been reported biologically transformed either through hydrolysis of two amide bonds or dehalogenation, while dehalogenation generally occurs under anoxic environments at an undetectable rate [9, 12]. Aerobic hydrolysis of TCC has been reported at a relatively fast rate [7, 13], which is more suitable for WWTPs. For wastewater sewage sludge, though generally nutrient and carbon-rich material, whether these substrates are sufficient or really available for functional microorganisms is unclear. Furthermore, aerobic and anaerobic processes are both included for most of WWTPs, whether the introduced functional microbes would adjust to the oxygen limitation or other electron acceptors conditions need to be verified. Under anoxic conditions, nitrate was considered a thermodynamically favorable electron acceptor, which could be reduced by various microorganisms. Numerous studies had confirmed the feasibility of nitrate addition for refractory compounds biodegradation [14, 15], particularly in sediment and soil remediation. However, whether the TCC-degrading bacteria could be potentially applied for TCC elimination with denitrification in wastewater treatment process is poorly understood. More important, within such complex biosystem, the xenobiotic species is generally easily eliminated from the indigenous microflora, and its colonization is a crucial factor for the sustainable function. Whether the activity of strain could be maintained by nitrate addition needs to be investigated.

Based on above questions, the objectives of this study are to (i) disclose the relation between the carbon nitrogen ratio and functional strain biomass under micro-aerobic and anaerobic conditions; (ii) confirm the TCC degradation ability of the biodegradative strain accompanied with denitrification; and (iii) explore the activity of TCC-degrading strain in real wastewater sewage sludge when nitrate was supplied. The present study would lay a basic foundation for TCC elimination in biosolid, sediment, and other TCCcontaminated anoxic environments.

\section{Materials and Methods}

\section{Chemicals}

3,4,4'-Trichlorocarbanilide (TCC, 99\%), 3,4-dichloroaniline (DCA, >98\%), and 4-chloroaniline (4CA, >98\%), chromatographical grade acetone, acetonitrile, and dichloromethane were purchased from Sigma-Aldrich (St. Louis, MO, USA). Other chemicals used were analytic grade at least.

\section{Enrichment, Isolation, and Identification of TCC-Degrading Strain}

The enrichment was derived from active sludge obtained from several WWTPs in Beijing (China). The mineral medium (MM) preparation and enrichment, isolation operation was similar with a previous study [7]. Identification was based on 16S rRNA gene and other basic biochemical tests. The BLAST program of NCBI (https://blast.ncbi.nlm. nih.gov/Blast.cgi) was used for $16 \mathrm{~S}$ rRNA gene sequences alignment. Phylogenetic tree was constructed by the neighbor-joining method with MEGA program (version 6.0). The 16S rRNA gene sequence had been deposited to Genbank database with an accession number of KT820194.

\section{Biodegradation Studies with Different Carbon Nitrogen Ratios}

The inoculum used for biodegradation studies was prepared as described previously [7]. The aerobic degradation of TCC was carried out in $50 \mathrm{~mL}$ flask with $20 \mathrm{~mL}$ MM contained $15.8 \mu \mathrm{M}$ TCC. For two anoxic conditions, the serum bottles were sealed with butyl rubber stoppers and aluminum caps after purging with purified nitrogen gas for approximately $5 \mathrm{~min}$ and more than $15 \mathrm{~min}$ to obtain dissolved oxygen (DO) concentration of about $0.5 \pm 0.15 \mathrm{mg} / \mathrm{L}$ (micro-aerobic) and $0.2 \pm 0.05 \mathrm{mg} / \mathrm{L}$ (anaerobic), respectively. Sodium acetate and potassium nitrate were supplied as electron donor/carbon source and electron acceptor in MM. The degradation of $15.8 \mu \mathrm{M}$ TCC was tested under carbon nitrogen ratios $(\mathrm{C} / \mathrm{N})$ of $4: 1$ and 10:1, where the amount of nitrate-nitrogen $\left(\mathrm{NO}_{3}-\mathrm{N}\right)$ was $21 \mathrm{mg} / \mathrm{L}$ for all tests. All media were sterilized by autoclaving at $121^{\circ} \mathrm{C}$ for $30 \mathrm{~min}$ before use. Potassium nitrate stock solution $(151.65 \mathrm{mg} / \mathrm{mL})$ was filtered with the $0.22 \mu \mathrm{m}$ filter (Shanghai XingYa Purification Material Co., China) before addition. Media without the inoculum worked as control. For each experimental condition, three biological replicates were prepared at every sampling time.

\section{TCC Degradation in Wastewater Sewage Sludge}

Wastewater sewage sludge (WSS) from Taiping WWTP (Harbin, China) was sampled for TCC degradation. Aliquot of WSS $(80 \mathrm{~mL})$ was added to $100 \mathrm{~mL}$ serum bottle and purged with nitrogen as described above. $\mathrm{NO}_{3}-\mathrm{N}$ (supplemented to nearly $21 \mathrm{mg} / \mathrm{L}$ ) and TCC-degrading strain TCC-1 (initial optical density of 0.035 ) were added if necessary. TCC was amended with stock solution in acetone (15.8 mM) to a final concentration of $15.8 \mu \mathrm{M}$. Six groups, (I) anaerobic with $\mathrm{NO}_{3}-\mathrm{N}$ and TCC; (II) anaerobic without $\mathrm{NO}_{3}-\mathrm{N}$ but with TCC and strain TCC-1; (III) anaerobic with $\mathrm{NO}_{3}-\mathrm{N}$, TCC and strain TCC-1; (IV) micro-aerobic 
with $\mathrm{NO}_{3}-\mathrm{N}$ and TCC; (V) micro-aerobic without $\mathrm{NO}_{3}-\mathrm{N}$ but with TCC and strain TCC-1; and (VI) micro-aerobic with $\mathrm{NO}_{3}-\mathrm{N}$, TCC and strain TCC-1 were conducted for TCC degradation. Groups without strain TCC-1 or without $\mathrm{NO}_{3}-\mathrm{N}$ were set as controls. The original $\mathrm{NO}_{3}-\mathrm{N}$ in WSS was detected less than $2 \mathrm{mg} / \mathrm{L}$. TCC and $\mathrm{NO}_{3}-\mathrm{N}$ were mixed well with sludge. Every after $60 \mathrm{~h}$, the top (about $30 \mathrm{~mL}$ ) aquatic phase was refreshed after setting, $15.8 \mu \mathrm{M}$ TCC and $21 \mathrm{mg} / \mathrm{L} \mathrm{NO} \mathrm{NO}_{3}-\mathrm{N}$ were amended for each group as a cycle (Table S1). All inoculations and controls were cultured in shaker at $140 \mathrm{rpm}$ at $30^{\circ} \mathrm{C}$. For each condition, three biological replicates were performed.

\section{Analytical Methods and Calculations}

TCC and its corresponding products (4CA and DCA) of the top aquatic phase were determined by a high-performance liquid chromatography (HPLC) as stated previously [7]. The concentrations of nitrate and nitrite were determined with an ion chromatograph (IC-1200, Thermal Fisher Co., Ltd., USA). For the quantification of strain TCC-1, the specific triclocarban-hydrolyzing amidase gene tcc A copy numbers were determined by quantitative PCR (qPCR) with primers pairs as shown in Table S2. Total bacteria were quantified with 16S rRNA gene. The preparation of biomass samples and detailed operation of qPCR were similar with previous references $[7,16]$. The mixture composition and PCR conditions were operated according to the instructions of SYBR Green Premix (TaKaRa Biotech, Dalian, China). Calibration curves (log DNA concentration versus an arbitrarily set cycle threshold value) were set based on serial dilutions of DNA from strain TCC-1 for
tccA and DNA from sludge sample for 16S rRNA gene. The copy number was obtained based on such calibration curves. Negative controls without template DNA were set. All samples were prepared in biological and technique triplicate. The calculation of transformation efficiency and rate were as described otherwise [7]. For all statistical tests, $P<0.05$ was considered as significantly different.

\section{Results and Discussion}

\section{Identification of TCC Biodegrading Strain TCC-1}

Among the several isolates, one isolate was identified by 16S rRNA gene sequence and it showed highest similarity to type strain members of Ochrobactrum, which was also similar with the reported TCC-degrading strain TCC-2 (Fig. 1). The strain was designated as Ochrobactrum sp. TCC-1, and the morphology is shown in Fig. S1. It can use alanine, glucose, fumarate, propionate, acetate, and lactate as carbon and energy source for growth. According to the isolation site, strain TCC- 1 is absolutely different from strain TCC-2, which was isolated from a river sediment (Shenzhen, China). However, the amidase gene $t c c \mathrm{~A}$ identified in strain TCC-2 could also be amplified from the genome of strain TCC-1. Amino acid sequences of TccA from strains TCC-1 and TCC-2 showed 100\% identity. This illustrated that a highly conservative amidase is responsible for the TCC hydrolysis in strain TCC-2 and strain TCC-1. Strain TCC-1 has the ability of TCC hydrolysis and generates $4 \mathrm{CA}$ and DCA in aerobic conditions (Fig. S2). TCC $(15.8 \mu \mathrm{M})$ was obviously decreased in the initial $4 \mathrm{~h}$ and
Fig. 1 Phylogenetic tree constructed by the neighborjoining method based on $16 \mathrm{~S}$ rRNA gene sequences of strain TCC-1, and other available Ochrobactrum type species, including TCC-degrading strain TCC-2. Bootstrap values (\%) are indicated at the nodes. The scale bar represents 0.005 substitutions per site, and GenBank accession numbers are in parentheses

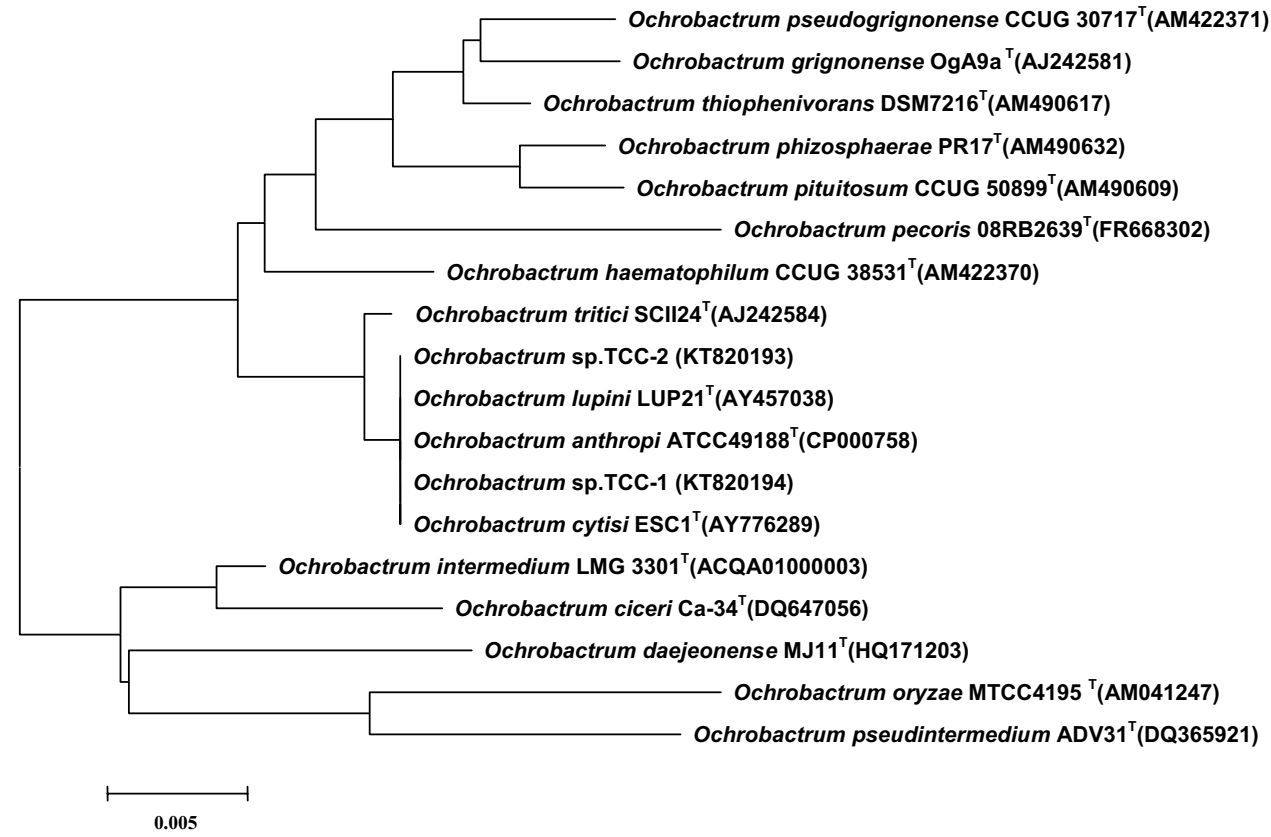


undetected after $42 \mathrm{~h}$. This process could be accelerated when glucose was supplemented, in which the biomass could grow. The metabolism could also be supported with nitrate as electron acceptor under anoxic conditions, which was based on the report that related nitrate reductases existed in such Ochrobactrum sp. [7].

\section{The Growth Supported by Nitrate Under Anoxic Conditions}

To enhance or maintain the biodegradation of TCC, the survival and activity of strain TCC-1 under anoxic conditions require alternative electron acceptors to support. Therefore, nitrate was supplied. Besides, to avoid the possibility of fermentation, sodium acetate was selected as carbon/energy sources and electron donor. Theoretically, reduction of one mole nitrate completely to nitrogen needs 5 mol electrons, for which, $0.625 \mathrm{~mol}$ acetate oxidation could offset. However, acetate would also serve as carbon source and energy for growth and metabolism. Thus, exceeding carbon nitrogen ratio $(\mathrm{C} / \mathrm{N})$ should be considered actually [17]. Different $\mathrm{C} / \mathrm{N}$ ratios were tested in this study. As shown in Fig. 2, for a similar inoculum size initially, the growth was not observed for the control group without nitrate and the biomass was weakly increased when $\mathrm{C} / \mathrm{N}$ was 4 under anaerobic condition. In the case of $\mathrm{C} / \mathrm{N}$ of 10 , strain TCC- 1 had more than doubled biomass at $24 \mathrm{~h}$ and 2.28 times increase at $48 \mathrm{~h}$. However, this was inferior to the micro-aerobic conditions. The growth was detected since the $12 \mathrm{~h}$ and lasted to the $60 \mathrm{~h}$ with a 6.72 times amplification in amount for $\mathrm{C} / \mathrm{N}$ of 4 and an order magnitude growth for $\mathrm{C} / \mathrm{N}$ of 10 . For the control provided with the same amount of sodium

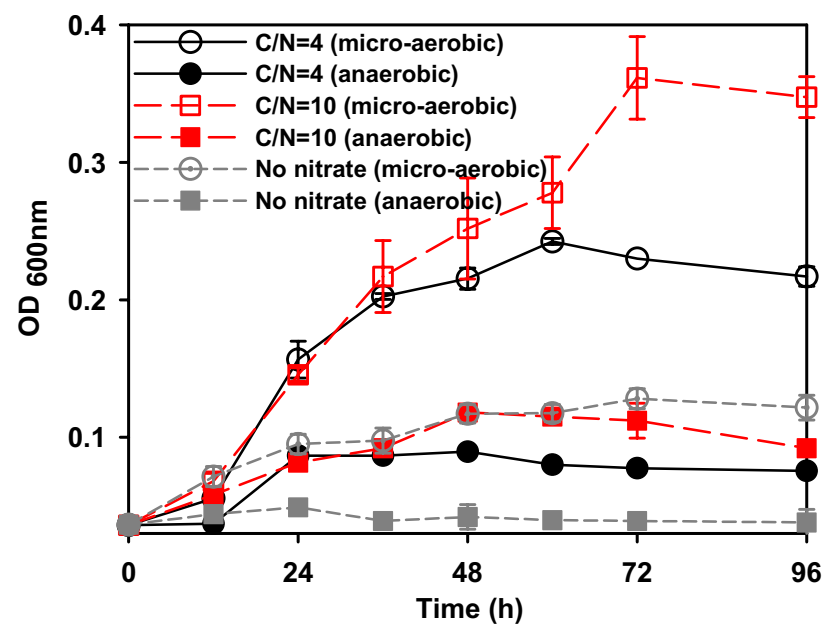

Fig. 2 Growth curves of strain TCC-1 with $\mathrm{C} / \mathrm{N}$ of 4 and 10 under micro-aerobic or anaerobic conditions. The carbon source was sodium acetate, and $\mathrm{NO}_{3}-\mathrm{N}$ supply was $21 \mathrm{mg} / \mathrm{L}$. The carbon source supply for the no nitrate control was as the same amount of $\mathrm{C} / \mathrm{N}$ of 10 acetate as the $\mathrm{C} / \mathrm{N}$ of 10 , strain TCC- 1 could have some growth initially under micro-aerobic condition using the residual oxygen, but would be distinctly less than that with nitrate amendment. The final biomass discrepancy could be nearly 3 times between groups with and without nitrate, which suggested the importance of electron acceptor supply. Nevertheless, the bacteria could have some preference on the electron acceptor. Oxygen should be the best selection and followed by nitrate. This could be seen from the anaerobic condition, where most part of nitrate was rapidly reduced with partial nitrite accumulation. Similarly, in the micro-aerobic condition, the utilization of nitrite was far behind of the nitrate, and nitrite had remnant until $60 \mathrm{~h}$. Besides, elimination of nitrate and nitrite were related with the carbon amendment. A higher carbon amount meant a more biomass and faster electron acceptor exhaustion. Under anaerobic conditions, nitrate seemed to be quickly transformed to nitrite in the first $12 \mathrm{~h}$ and disappeared within $48 \mathrm{~h}$ (Fig. 3a). Under micro-aerobic conditions, time periods of nitrate reduction $(0-60 \mathrm{~h})$ were corresponding to those for biomass accumulation (Figs. 2, 3b). The maximum OD value for the $\mathrm{C} / \mathrm{N}$ of 10 was at $72 \mathrm{~h}$, a little later than that of $\mathrm{C} / \mathrm{N}$ of 4 at $60 \mathrm{~h}$, which was likely due to the higher carbon and energy source provided. The biomass for $\mathrm{C} / \mathrm{N}$ of 10 was about 1.5 times of that for $\mathrm{C} / \mathrm{N}$ of 4 , which illustrated that more growth and longer period of activity could be supported when more carbon and energy sources input and implied the significance of energy source supply. No matter what $\mathrm{C} / \mathrm{N}$ was, nitrite had a longer retention time in micro-aerobic than that in anaerobic condition (Fig. 3). Collectively, the growth was influenced by types of electron acceptor and $\mathrm{C} / \mathrm{N}$, and a higher $\mathrm{C} / \mathrm{N}$ is beneficial to the growth of strain TCC-1. The survival and thrive of the TCC-degrading strain in severe environments, where oxygen was scarce, are meaningful for such recalcitrant pollutant removal, because TCC was extensively carried by sludge and sediments, in which oxygen was generally limited. The TCC concentration could reach up to $\mathrm{mg} / \mathrm{kg}$ level [5] and the half-life in such environments was estimated to $150-540 \mathrm{~d}[18,19]$. If the application of such functional strain could shorten the degradation time, it would eliminate many severe environmental problems and risks. The alternative electron acceptors like nitrate would potentially decline the limitation in realistic bioremediation with strain TCC-1 bioaugmentation.

\section{The Effect of C/N on the TCC Degradation}

The growth and metabolism of strain TCC-1 was influenced by the quantity of energy and terminal electron acceptors, which further influenced the TCC removal. For $\mathrm{C} / \mathrm{N}$ of 4 and 10, in micro-aerobic conditions, the 4CA formation efficiency was $66.53 \pm 0.69 \%$ and $81.99 \pm 5.1 \%$ at 
Fig. 3 Reduction of nitrate and nitrite under anaerobic (a) and micro-aerobic (b) conditions with $\mathrm{C} / \mathrm{N}$ of 4 and 10 . Nitrate was supplied as electron acceptor to support growth and TCC hydrolysis

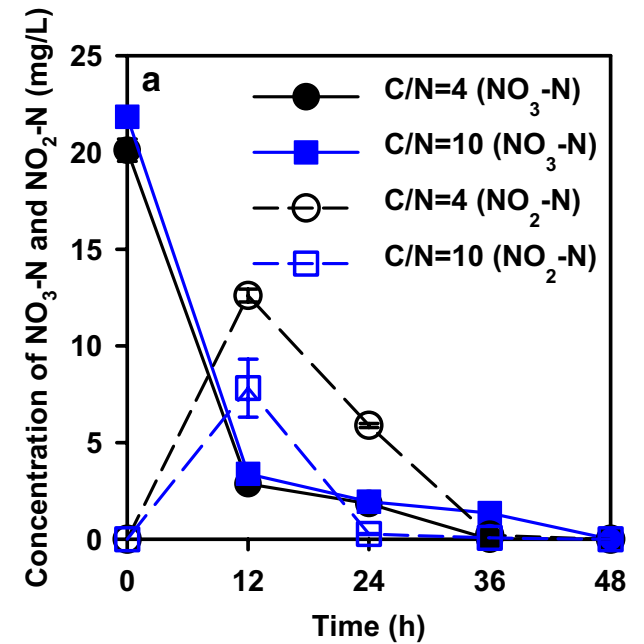

$24 \mathrm{~h}$, respectively, accompanied with $48.25 \pm 1.19 \%$ and $63.17 \pm 11.47 \%$ DCA formation. The maximum $4 \mathrm{CA}$ formation efficiency was at $96 \mathrm{~h}$ of $93.60 \pm 0.69 \%$ for $\mathrm{C} / \mathrm{N}$ of 4 and at $72 \mathrm{~h}$ of $94.94 \pm 3.15 \%$ for $\mathrm{C} / \mathrm{N}$ of 10 (Fig. $4 \mathrm{~b}, \mathrm{~d}$ ). The maximum average formation rates of $4 \mathrm{CA}$ for the two $\mathrm{C} / \mathrm{N}$ ratios were $0.44 \pm 0.018 \mu \mathrm{M} / \mathrm{h}$ occurred in the stage of $12-24 \mathrm{~h}$ and $1.27 \pm 0.06 \mu \mathrm{M} / \mathrm{h}$ in the stage of $0-12 \mathrm{~h}$. For DCA, the corresponding data were $0.39 \pm 0.035 \mu \mathrm{M} / \mathrm{h}$ and $0.96 \pm 0.20 \mu \mathrm{M} / \mathrm{h}$. The maximum DCA formation efficiency was $76.84 \pm 0.51 \%$ and $73.96 \pm 10.9 \%$ for the two $\mathrm{C} / \mathrm{N}$ ratios. Although products formation for the group without nitrate was comparable with those of with nitrate supply, the biomass difference was obvious (Fig. 2). Overall, in oxygen limited conditions, the increase of acetate improved the TCC transformation. The DCA accumulation had a plateau in both $\mathrm{C} / \mathrm{N}$ ratios in the micro-aerobic case (Fig. 4b, d), and the reason was warranted by other researches. It is postulated that DCA suffered from a dynamic balance in some unknown reactions. The 4CA formation efficiency was less in anaerobic conditions at $24 \mathrm{~h}$, which was consistent with the biomass difference. Only $49.82 \pm 0.37 \% 4 \mathrm{CA}$ was accumulated at $24 \mathrm{~h}$ for $\mathrm{C} / \mathrm{N}$ of 4 in anaerobic experiments, and the corresponding value was $60.0 \pm 0.72 \%$ for $\mathrm{C} / \mathrm{N}$ of 10 . A higher $\mathrm{C} / \mathrm{N}$ made obviously larger yields of 4CA and DCA in the front half stage, and a higher $\mathrm{C} / \mathrm{N}$ also catered to a delayed or longer stable phase (Fig. 4a, c). The maximum formation rates of $\mathrm{C} / \mathrm{N}$ of 4 were $0.47 \pm 0.033 \mu \mathrm{M} / \mathrm{h}$ and $0.32 \pm 0.002 \mu \mathrm{M} / \mathrm{h}$ for $4 \mathrm{CA}$ and DCA, which located within 0 to $12 \mathrm{~h}$ and 12 to $24 \mathrm{~h}$, respectively. $A$ raised $\mathrm{C} / \mathrm{N}$ made the maximum reaction
Fig. 4 Chloroanilines yields under anaerobic (a, c) and micro-aerobic $(\mathbf{b}, \mathbf{d})$ conditions with $\mathrm{C} / \mathrm{N}$ of 4 and 10 by strain TCC-1 in mineral medium (MM). The carbon source supply for the no nitrate controls was as the same amount of $\mathrm{C} / \mathrm{N}$ of 10
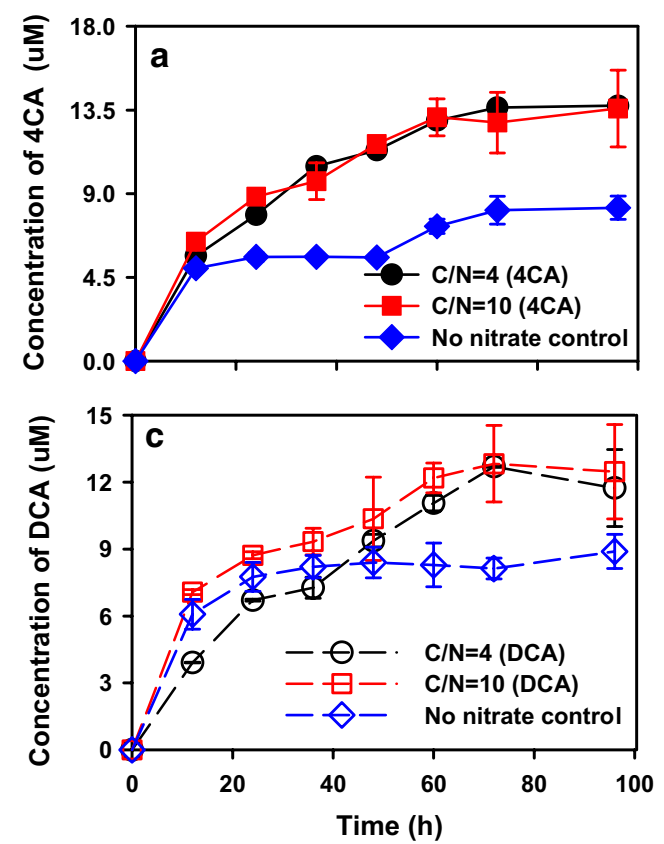

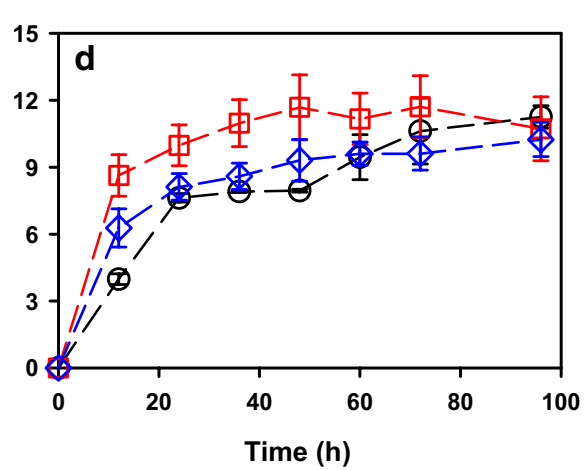


rate happened in 0 to $12 \mathrm{~h}$, which were $0.71 \pm 0.049 \mu \mathrm{M} / \mathrm{h}$ and $0.79 \pm 0.012 \mu \mathrm{M} / \mathrm{h}$ for $4 \mathrm{CA}$ and DCA, respectively. Meanwhile, like the micro-aerobic cases, the products formation tended to stay in a plateau after the maximum biomass growth. The maximum 4CA and DCA formation was comparable with their counterparts in micro-aerobic conditions. This illustrated that the survival was indispensable for the TCC transformation, which can be enhanced by strain TCC-1 propagation. As for TCC, the removal trends were agreed with the products formation. Micro-aerobic and high $\mathrm{C} / \mathrm{N}$ conditions were undoubtedly in favor of the TCC degradation. The anaerobic condition was comparable with the micro-aerobic one if elevating the $\mathrm{C} / \mathrm{N}$. Such environments like sewage sludge and sediments, the carbon resources are usually unlikely at a low level. When some inexpensive electron acceptors supplemented to make up the limitation of oxygen, the biodegradation of some recalcitrant like TCC could be considered. Previous studies have reported on the degradation of naphthenic acid [20], pyrene [15], polybrominated diphenyl ethers (PBDEs), and polycyclic aromatic hydrocarbons (PAHs) [14] with nitrate supplement.

\section{TCC Degradation with Nitrate as Electron Acceptor in Wastewater Sewage Sludge}

Generally, most of discharged TCC initially exists in domestic wastewater and then is input into WWTPs, in which it has increased opportunity to contact with sludge. Many reports have stated that TCC easily adsorbed on sewage sludge during the wastewater treatment, which was further output in the form of biosolid. If TCC in WSS could be transformed and detoxified before the output of sewage sludge, it would decrease the source of TCC from biosolid. Meanwhile, COD in WSS could potentially supply quantities of carbon and energy sources. This part of energy could support the metabolism and growth of TCCdegrading strain. To avoid the increase of sewage sludge amount, anaerobic treatment may be selected. Therefore, the colonization of TCC-degrading bacteria or at least the activity maintenance is essential for the succession of this process. In this study, we tested the TCC transformation in WSS by strain TCC-1 with nitrate as electron acceptor under anoxic conditions. The transformation products of TCC were detected every $60 \mathrm{~h}$ to determine the time for next TCC and/or nitrate amendment by comparison with the theoretical amount of 4CA and DCA. TCC $(15.8 \mu \mathrm{M})$ and/or $\mathrm{NO}_{3}-\mathrm{N}(21 \mathrm{mg} / \mathrm{L})$ were supplied for each time after the aquatic phase refreshment as shown in Table S1. Before the next addition, the biomass was sampled for the quantification of strain TCC-1 with gene $t c c \mathrm{~A}$ and the whole bacteria with 16S rRNA gene. The process was kept several cycles to evaluate the probable running time with once strain TCC-1 addition. As shown in Fig. 5, it could be seen that 4CA and DCA were accumulated along with time. The subsequent transformation efficiencies were $94.97 \pm 5.22 \%, 80.60 \pm 3.83 \%$, and $81.63 \pm 5.80 \%$ for $4 \mathrm{CA}$ under anaerobic conditions in three cycles, and the corresponding data for DCA were $89.50 \pm 6.91 \%, 86.66 \pm 7.17 \%$, and $83.07 \pm 3.40 \%$, respectively. Under micro-aerobic conditions, 4CA had comparable transform efficiencies for the first two cycles but not for the third cycle, which was obviously lower than the first two cycles. This trend was also applicable for the DCA transformation, which was particularly lower than theoretical stoichiometric data $(P<0.05)$ in the third cycle. Chloroanilines yields may be influenced by adsorption and other reasons. For one thing, the sorption of chloroanilines on sludge matrix may make measurement incorrect. For another, some bacteria could transform them by biodegradation and polymerization particularly when oxygen existed [21, 22]. We had isolated a chloroanilinesdegrading strain from the sludge which could use 4CA
Fig. 5 Concentration of 4CA and DCA detected before each refresh of aquatic phase (a) and quantification of gene $t c c \mathrm{~A}$ associated with activity of strain TCC-1 in wastewater sewage sludge under anaerobic and micro-aerobic conditions for each cycle (b)
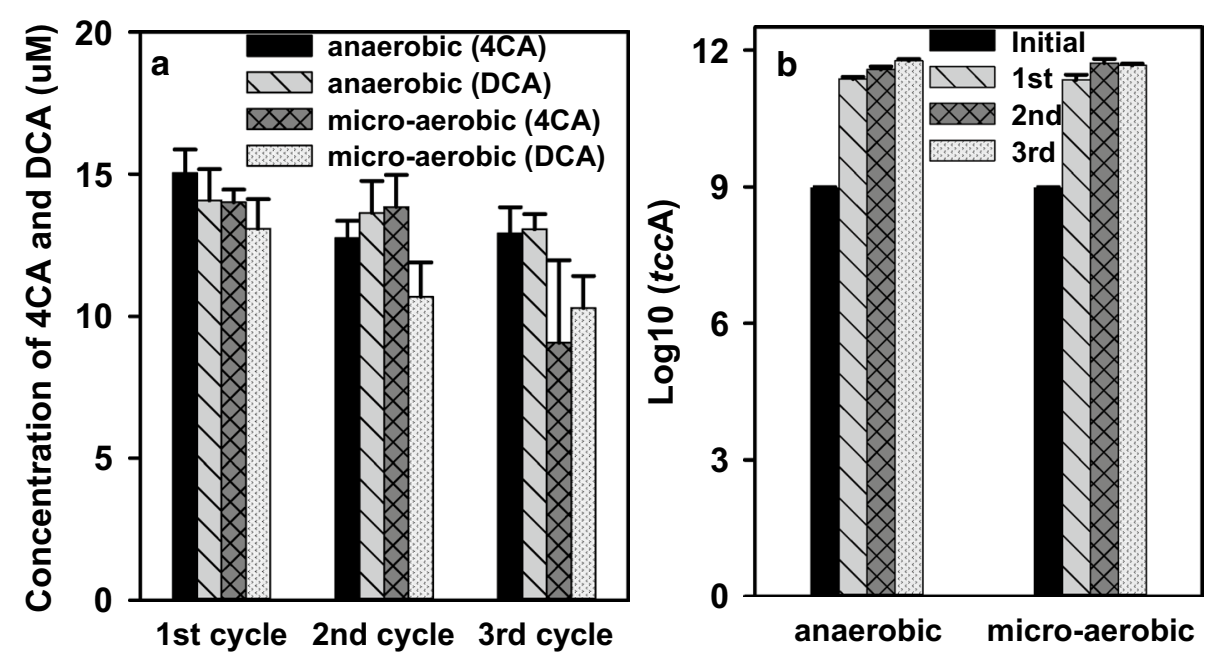
and DCA as carbon and energy sources (data not shown). This also might be related with the activity of functional strain or its abundance in microbial communities. After all, species existing in sewage sludge were more active in micro-aerobic environment, which would compete with the non-indigenous species strain TCC-1 for limited energy source and electron acceptor. As we all know, such organic compounds like organic acid, monosaccharide are eligible energy sources for most bacteria, including strain TCC-1. However, the multiplication was limited after the second cycle no matter for the whole biomass or strain TCC-1, and the former had a little higher increase than the latter (1.36 vs. 1.13 times, Fig. 5b, S3). This was in accordance with products formation. Whether the restriction of easily available energy sources was the main determinant need further study. The volatile suspended solid of the sample was around $3 \mathrm{~g} / \mathrm{L}$, which was not very high. In contrast, in anaerobic cases, some strict aerobic bacteria would be eliminated, and anaerobes generally have relatively slow metabolism and growth, which was in accordance with a $10.97 \pm 2.79 \%$ dry weight difference between micro-aerobic and anaerobic biomass, so the resource competition would not be that drastic. This was in favor of the colonization of the facultative strain TCC-1. The copy number of $t c c \mathrm{~A}$ gene was comparable with that in micro-aerobic condition $(P=0.81)$. Chloroanilines formation efficiencies under anaerobic condition were all over $80 \%$, meaning most of TCC had been transformed to more biodegradable products. Besides, there seemed to be no functional species in the original sewage sludge, for chloroanilines were not detected in aquatic phase for groups (I) and (IV). The total biomass had a decrease of $8-10 \%$ as a whole for microaerobic or anaerobic tests by copy numbers (Fig. S3). For groups (II) and (V), though strain TCC-1 could do some hydrolysis and the biomass had a relatively small increase, the TCC removal and the growth for total biomass were limited without nitrate (Fig. S3). The untreated TCC may be transferred to sludge phase, for little residue existed in aquatic phase. Actually, many members in the sewage sludge could use nitrate as electron acceptor. Some complex organics could be transformed to simple organics by some members and these products were further used during nitrate reduction. To what extent TCC had effect on such bacteria who took part in nitrate reduction or complex organics fermentation was unknown. The added nitrate could be exhausted sufficiently in the first two cycles but had a little residue for the third cycle and following cycle. The activity of those members responsible for nitrate reduction seemed to be inhibited either by energy deficiency or by TCC. Factually, this process may be relieved if the sewage sludge flowed or renewed. This could be realized in actual WWTPs. The amended dose of strain TCC-1 in this study was tiny, which could be supplemented periodically if necessary in real bioremediation. When the bioremediation of TCC operated in soil or sediment environments, the biomass could be increased and electron acceptors could be supplied intermittently to guarantee the bioaugmentation and biostimulation performance.

\section{Conclusions}

Biotransformation of TCC to chloroanilines by Ochrobactrum sp. TCC-1 under anoxic conditions could be supported by nitrate. Biomass growth or activity maintenance is vital for TCC removal in anoxic process, which could be enhanced by more energy supply and alternative electron acceptor supplementation. Both micro-aerobic and anaerobic conditions had relatively high chloroanilines yields by comparison with groups without nitrate supply. For wastewater sewage sludge, strain TCC-1 could colonize and efficiently work on TCC hydrolysis for once amendment, which could be enhanced by functional strain and extra electron acceptor replenishment. This is the first report on bioremediation of TCC-carried sewage sludge with introduced TCC-degrading strain.

Acknowledgements This work was supported by the National Natural Science Foundation of China (No. 31500084), the Key Deployment Project of Chinese Academy of Sciences (No. ZDRWZS-2016-5-5), and the State Key Laboratory of Urban Water Resource and Environment of Harbin Institute of Technology (No. 2016DX03).

\section{References}

1. Rulkens W (2008) Sewage sludge as a biomass resource for the production of energy: overview and assessment of the various options. Energy Fuels 22(1):9-15

2. Mcclellan K, Halden RU, Ternes T (2010) Pharmaceuticals and personal care products in archived U.S. biosolids from the 2001 EPA National Sewage Sludge Survey. Water Res 44(2):658-668

3. Yang G, Zhang G, Wang H (2015) Current state of sludge production, management, treatment and disposal in China. Water Res 78:60-73

4. Heidler J, Amir Sapkota A, Halden RU (2006) Partitioning, persistence, and accumulation in digested sludge of the topical antiseptic triclocarban during wastewater treatment. Environ Sci Technol 40:3634-3639

5. Sherburne JJ, Anaya AM, Fernie KJ, Forbey JS, Furlong ET, Kolpin DW, Dufty AM, Kinney CA (2016) Occurrence of triclocarban and triclosan in an agro-ecosystem following application of biosolids. Environ Sci Technol 50(24):13206-13214

6. Andrade NA, Lozano N, McConnell LL, Torrents A, Rice CP, Ramirez M (2015) Long-term trends of PBDEs, triclosan, and triclocarban in biosolids from a wastewater treatment plant in the Mid-Atlantic region of the US. J Hazard Mater 282:68-74

7. Yun H, Liang B, Qiu J, Zhang L, Zhao Y, Jiang J, Wang A (2017) Functional characterization of a novel amidase involved in biotransformation of triclocarban and its dehalogenated congeners in Ochrobactrum sp. TCC-2. Environ Sci Technol 51(1):291-300 
8. Gao L, Yuan T, Cheng P, Bai Q, Zhou C, Ao J, Wang W, Zhang $H$ (2015) Effects of triclosan and triclocarban on the growth inhibition, cell viability, genotoxicity and multixenobiotic resistance responses of Tetrahymena thermophila. Chemosphere 139:434-440

9. Venkatesan AK, Pycke BF, Barber LB, Lee KE, Halden RU (2012) Occurrence of triclosan, triclocarban, and its lesser chlorinated congeners in Minnesota freshwater sediments collected near wastewater treatment plants. J Hazard Mater 229-230(3):29-35

10. Carey DE, Mcnamara PJ (2016) Altered antibiotic tolerance in anaerobic digesters acclimated to triclosan or triclocarban. Chemosphere 163:22-26

11. Carey DE, Zitomer DH, Hristova KR, Kappell AD, Mcnamara PJ (2015) Triclocarban influences antibiotic resistance and alters anaerobic digester microbial community structure. Environ Sci Technol 50(1):126-134

12. Miller TR, Heidler J, Chillrud SN, Delaquil A, Ritchie JC, Mihalic JN, Bopp R, Halden RU (2008) Fate of triclosan and evidence for reductive dechlorination of triclocarban in estuarine sediment. Environ Sci Technol 42:4570-4576

13. Mulla SI, Hu A, Wang Y, Sun Q, Huang SL, Wang H, Yu CP (2016) Degradation of triclocarban by a triclosan-degrading Sphingomonas sp. strain YL-JM2C. Chemosphere 144:292-296

14. Xu M, Zhang Q, Xia C, Zhong Y, Sun G, Guo J, Yuan T, Zhou J, He Z (2014) Elevated nitrate enriches microbial functional genes for potential bioremediation of complexly contaminated sediments. ISME J 9(2):1932-1944
15. Yang X, Ye J, Lyu L, Wu Q, Zhang R (2013) Anaerobic biodegradation of pyrene by Paracoccus denitrificans under various nitrate/nitrite-reducing conditions. Water, Air, Soil Pollut 224(5):1-10

16. Purkhold U, Pommereningröser A, Juretschko S, Schmid MC, Koops HP, Wagner M (2000) Phylogeny of all recognized species of ammonia oxidizers based on comparative $16 \mathrm{~S}$ rRNA and amoA sequence analysis: implications for molecular diversity surveys. Appl Environ Microbiol 66(12):5368-5382

17. Chen C, Ren N, Wang A, Yu Z, Lee DJ (2008) Simultaneous biological removal of sulfur, nitrogen and carbon using EGSB reactor. Appl Microbiol Biotechnol 78(6):1057-1063

18. Rolf UH, Daniel HP (2005) Co-occurrence of triclocarban and triclosan in US water resources. Environ Sci Technol 39:1420-1426

19. Ying GG, Yu XY, Kookana RS (2007) Biological degradation of triclocarban and triclosan in a soil under aerobic and anaerobic conditions and comparison with environmental fate modelling. Environ Pollut 150(3):300-305

20. Dong F (2014) Anoxic biodegradation of naphthenic acid using nitrite as an electron acceptor. Master thesis http://hdl.handle. net/10388/ETD-2014-10-1802

21. Arora PK (2015) Bacterial degradation of monocyclic aromatic amines. Front Microbiol 6:1-14

22. Bartha R, Pramer D (1968) Pesticide transformations: production of chloroazobenzenes from chloroanilines. Science 161(3841):582-583 